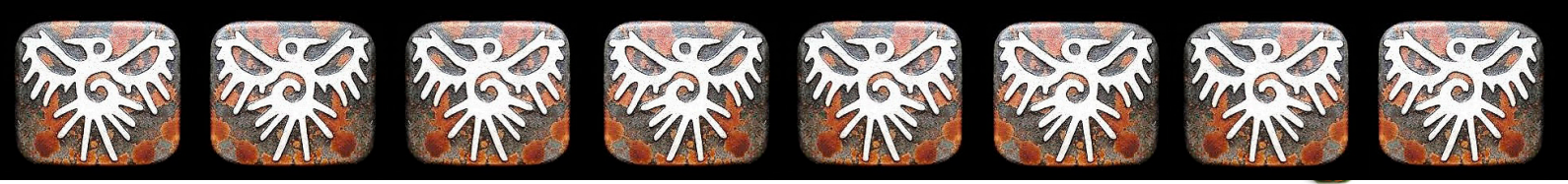

Artículo de reflexión E10A08. * Recibido: 20-02-2017. * Aprobado versión final: 22-02-2018. JEL: G21, K33. Pp. 81-101

\title{
Fortalecimiento de la banca en Méjico después de la crisis 1994-1995, y sus efectos.
}

\author{
Banking strengthening in Mexico \\ after the crisis of 1994-1995, and its effects.
}

Octavio Avendaño Carbellido

\section{MÉJICO}

Resumen: El presente estudio analiza el fortalecimiento de la banca en Méjico a partir de la crisis financiera y bancaria de 1994-1995, promovida principalmente por los organismos financieros internacionales como el BIRF (Banco Mundial), así como la adopción de los acuerdos del Comité de Supervisión Bancaria de BASILEA, que generaron el diseño normativo, prudencial e institucional que hoy dan solidez al Sistema Bancario. Este trabajo muestra, además, que esa fortaleza coadyuvó a que Méjico enfrentara satisfactoriamente los efectos de la crisis financiera originada en EUA en 2007-2008.

Palabras clave: banca en méjico; crisis financiera; evolución de la banca; servicios financieros.

Abstract: The study analyzes the Banking strengthening in Mexico from the financial and banking crisis of 1994-1995, driven mainly by international financial organizations such as the IBRD (World Bank), as well as the adoption of the Bassel Committee on Banking Supervision Principles, which generated the normative, prudential and institutional design that enhanced the Banking System. This work also shows that this strength supported Mexico to face satisfactorily the effects of the financial crisis originated in the USA during 2007-2008.

Keywords: banking in mexico; financial crisis; evolution of banking; financial services.

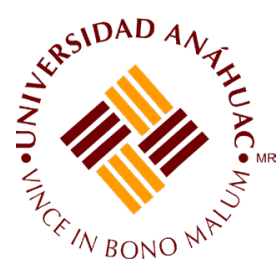

Octavio Avendaño es Doctor y Magíster en Derecho por la UNAM; miembro del Sistema Nacional de Investigadores (SNI/CONACyT). Nivel I y Profesor investigador en la Facultad de Derecho de la Universidad Anáhuac Méjico Sur. Es miembro de la Asociación Nacional de Doctores en Derecho, Colegio de Profesionistas, A.C. y miembro de la Sociedad Internacional de Farmacoeconomía. Sus líneas de investigación son Derecho Corporativo y Financiero, y es autor de libros, capítulos de libros y de artículos publicados en reconocidas revistas internacionales.

Contacto: avendano.octavio@gmail.com 


\section{O fortalecimento da banca mexicana depois da crise de 1994-1995, e seus efeitos.}

Resumo: Este estudo analiza o fortalecimento da Banca Mexicana a partir da crise financeira e bancária de 1994-1995, promovida principalmente pelos organismos internacionais como o BIRD (Banco Internacional para Reconstrução e Desenvolvimento), e também a adoção dos Acordos do Comitê de Supervisão Bancária da BASILEIA, que geraram o marco normativo, prudencial e institucional que atualmente dão solidez ao Sistema Bancario. Este trabalho mostra que essa solidez foi uma peça fundamental para que o México pudesse enfrentar satisfatoriamente os efeitos da crise financeira originada nos EUA em 2007-2008.

Palavras-chave: banca no méxico; crise financeira; evolução da banca; serviços financeiros.

\section{La Banca en Méjico}

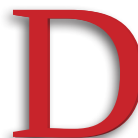

e acuerdo con Tello (2006: 29), el sistema bancario mejicano registra una gran concentración desde su nacimiento, la cual se acentuó durante la década de los setenta con el proceso de concentración oligopólica. Para 1981 tan solo Bancomer y Banamex concentraban prácticamente la mitad del mercado.

A noviembre de 2017, el sector de banca múltiple se encuentra integrado por cuarenta y ocho entidades, sin embargo, siete de ellas concentran prácticamente el $80 \%$ del total de activos del sistema y en su mayoría son extranjeras, como puede observarse en el siguiente cuadro:

Cuadro 1. Nivel de concentración y capital de la banca en Méjico (2017).

\begin{tabular}{|l|c|c|}
\hline \multicolumn{1}{|c|}{ BANCO } & \% DE ACTIVO TOTAL & CAPITAL \\
\hline BBVA BANCOMER & 22.6 & Extranjero \\
SANTANDER & 15.1 & Extranjero \\
BANAMEX & 13.2 & Extranjero \\
BANORTE & 11.5 & Nacional \\
HSBC & 7.4 & Extranjero \\
SCOTIABANK & 4.4 & Extranjero \\
INBURSA & 4.6 & Nacional \\
TOTAL & 78.8 & \\
& (62.7 \% extranjero vs. 16.1 \\
\end{tabular}

Fuente: Elaboración propia desde Boletín Estadístico de Banca Múltiple, CNBV, noviembre, 2017. Principales rubros del balance general y estado de resultados. Méjico, 2017. www.cnbv.gob.mx. 
Esta concentración no favorece la competencia ni las condiciones para que el usuario acceda al financiamiento, tanto por el costo del dinero en sí mismo como por las altas comisiones y la mala/regular calidad en el servicio, los cuales difícilmente pueden mejorar si tan solo tres entidades concentran más del $50 \%$ del mercado (ver fig. 1)

La Comisión Federal de Competencia Económica (COFECE) ha sostenido que la concentración en el sistema bancario mejicano "refleja potenciales limitaciones en las condiciones de competencia y libre concurrencia que inciden negativamente en el bienestar de los consumidores a través de los precios, la calidad y la variedad de servicios financieros que adquieren. Esta concentración se puede explicar en la medida en que el sistema financiero tiende a presentar fallas de mercado y restricciones a la competencia, tanto estructurales (por ejemplo, presencia de economías de escala, alcance o red, diferenciación de productos, costos de traspaso), como de comportamiento" (COFECE, 2014: 15). Al estar concentrado el mercado en tan pocas entidades, aumenta significativamente el riesgo de todo el sistema en caso de descapitalización o quiebra de los principales bancos.

\section{Los riesgos en la banca y el papel de Basilea}

Por su propia naturaleza, el negocio bancario tiene una alta exposición al riesgo, tanto por factores internos como externos. Lizarzaburu y Berggrun (2012) sostienen que la globalización e internacionalización de la banca en general ha debilitado las garantías nacionales contra el colapso bancario, pero al mismo tiempo ha hecho necesarias las salvaguardias eficaces más urgentes, como se evidenció con la crisis iniciada en EUA en 2008 y anteriormente la crisis asiática de 1997 y otras anteriores que datan de principios de los años 70, como la crisis del petróleo o el famoso crack de 1929.

Por ello, a nivel internacional se hizo necesario contar con un marco prudencial para reducir los riegos en la banca a través de una adecuada supervisión de los entes reguladores, lo cual dio origen al Comité de Supervisión Bancaria de Basilea (Basilea).

\section{A. El Comité de Supervisión Bancaria de Basilea}

Basilea nace en 1974 en el seno del Banco de Pagos Internaciones (BPI), el cual, de acuerdo con Avendaño (2010:167), se erige como una de las instituciones más importantes y antiguas del Sistema Financiero Internacional, cuya principal función es ser el banco de los bancos centrales del mundo y coadyuvar en operaciones financieras entre los diversos países, y entre estos y los organismos financieros internacionales. 
Conforme a su carta estatutaria (Basilea, 2013: 1) es el principal comité normativo internacional para la regulación prudencial de los bancos y constituye un foro de cooperación en materia de supervisión bancaria. Su mandato es mejorar la regulación, la supervisión y las prácticas bancarias en todo el mundo con el fin de afianzar la estabilidad financiera.

Actualmente, los países que forman parte de este comité son: Argentina, Australia, Bélgica, Brasil, Canadá, China, Unión Europea, Francia, Alemania, Hong Kong, India, Indonesia, Italia, Japón, Corea, Luxemburgo, Méjico, Países Bajos, Rusia, Arabia Saudita, Singapur, Sudáfrica, España, Suecia, Suiza, Turquía, Reino Unido y los Estados Unidos.

Las instituciones que representan a Méjico en este organismo son el Banco de México (Banxico) y la Comisión Nacional Bancaria y de Valores (CNBV).

Este cuerpo colegiado lleva a cabo su mandato a través de actividades como: a) Intercambiar información sobre la evolución del sector bancario y los mercados financieros, b) Compartir asuntos, estrategias y técnicas de supervisión; c) Establecer y promover normas internacionales, directrices y buenas prácticas; d) Abordar las lagunas de regulación y supervisión y e) Vigilar la aplicación de normas (Basilea 2013: 2).

Basilea no cuenta con personalidad jurídica propia ni sus recomendaciones tienen fuerza vinculatoria, sin embargo, suelen ser aceptadas por los países a través de sus respectivos supervisores bancarios.

\section{Los acuerdos de Basilea}

De 1988 a 2013 Basilea ha emitido una serie de acuerdos, reglas y recomendaciones a fin de mitigar la exposición al riesgo de los bancos, con énfasis en la capitalización. Estos acuerdos son conocidos como Basilea I, II y III. Su alcance y pilares pueden observarse de manera sintética en los siguientes cuadros:

Cuadro 2. Resumen del alcance de los acuerdos de Basilea

\begin{tabular}{|l|l|}
\multicolumn{2}{|c|}{ ACUERDOS DE BASILEA } \\
\hline \multirow{3}{*}{ BASILEA I (1988) } & $\begin{array}{l}\text { Pilar I: Componentes de capital } \\
\text { Pilar II: Carga de riesgo } \\
\text { Pilar III: Cociente de estándar universal } \\
\text { Pilar IV: Implementación de los acuerdos }\end{array}$ \\
\hline
\end{tabular}




\section{ACUERDOS DE BASILEA}

\begin{tabular}{|l|l}
\hline BASILEA II (2004) & $\begin{array}{l}\text { Pilar I: Requerimientos mínimos de capital } \\
\text { Pilar II: Proceso de supervisión bancaria } \\
\text { Pilar III: Disciplina de mercado }\end{array}$ \\
BASILEA III (2013) & $\begin{array}{l}\text { Reforma: Mejora de captura de riesgos } \\
\text { Reforma: Introducción de una ratio de apalancamiento } \\
\text { Reforma: Aumento de nivel de los requerimientos de } \\
\text { capital }\end{array}$
\end{tabular}

Cuadro 3. Resumen de la evolución de los acuerdos de BASILEA

\begin{tabular}{|l|l|}
\hline BASILEA I & $\begin{array}{l}\text { Propone solamente requisitos de capital mínimo para } \\
\text { los bancos internacionalmente activos e invita a otras } \\
\text { instituciones a su regulación en materia de operaciones } \\
\text { bancarias } \\
\text { Propone establecer requerimientos de capital necesarios } \\
\text { para asegurar la protección de las entidades frente a los } \\
\text { riesgos financieros yoperativos } \\
\text { BASILEA III }\end{array}$ \\
$\begin{array}{l}\text { Propone reformas para fortalecer la regulación, } \\
\text { supervisión y gestión de riesgos del sector bancario. } \\
\text { Aumenta requerimientos de capital. }\end{array}$ \\
\hline
\end{tabular}

Fuente: Elaboración propia con información de Bank for International Settlements, http://www.bis.org y de la Comisión Nal. Bancaria y de Valores (CNBV), http://www.cnbv.gob.mx.

\section{a) Basilea I}

Basilea publicó en 1997 los Principios Básicos para una Supervisión Bancaria Eficaz. Incluyó que contenía una definición de capital regulatorio, estableció un sistema de ponderación de exposiciones y sugería el capital mínimo que las entidades debían tener en relación con sus activos ponderados por riesgo (crédito, mercado y tipo de cambio) en un $8 \%$.

\section{b) Basilea II}

En 2006, Basilea emitió una versión revisada de dichos principios, los cuales se alinearon a diversas disposiciones en materia de valores y seguros, lucha contra el blanqueo de dinero y fomento a la transparencia. De acuerdo con el propio organismo (Basilea, 2006: 2), se trata de 25 preceptos agrupados en siete grandes categorías: 1) Objetivos, independencia, potestades, transparencia y cooperación (PB 1); 2) Licencias y estructuras (PB 2 a 5); 3) Regulación y requisitos prudenciales (PB 6 a 18); 4) Métodos para la supervisión bancaria continua (PB 19 a 21); 5) Contabilidad y divulgación 
(PB 22), 6) Potestades correctivas del supervisor (PB 23); y 7) Supervisión bancaria consolidada y transfronteriza (PB 24 y 25)

En materia de capitalización y riesgos (principios 5 a 16), se incorporaron aspectos que deben considerar los supervisores de las instituciones de crédito como: suficiencia de capital, proceso para la gestión del riesgo, riesgo de crédito, límites de exposición a grandes riesgos, riesgo país y riesgo de transferencia, riesgo de mercado, riesgo de liquidez, riesgo operacional y riesgo de tipos de interés en la cartera de inversión (Basilea: 2006).

Basilea II tuvo por objetivo construir una base sólida para la regulación prudente del capital, la supervisión y la disciplina de mercado, así como perfeccionar la gestión del riesgo y la estabilidad financiera (Basilea, 2004: p.5) y, de acuerdo con Martínez (2007:466), está dirigida hacia una mayor conciencia en el manejo y control de riesgos, ya que derivado de la aplicación de estos principios se monitorea no solo el riesgo financiero, sino que ahora se complementa el análisis de la operación financiera de los bancos con base en mayores riesgos como el operativo (legal, recursos humanos, tecnologías de la información) y el riesgo de mercado.

\section{c) Basilea III}

De acuerdo con Basilea (2011:1), estos acuerdos fortalecen la regulación, supervisión y gestión de riesgos del sector bancario y persiguen: a) mejorar su capacidad para afrontar perturbaciones ocasionadas por tensiones financieras o económicas de cualquier tipo; b) mejorar la gestión de riesgos y el bueno gobierno en los bancos; y c) reforzar la transparencia y la divulgación de información de dichas entidades.

Basilea III fomenta la regulación de los bancos a título individual (dimensión microprudencial) para aumentar la capacidad de reacción de cada institución en periodos de tensión, pero también a los riesgos sistémicos (dimensión macroprudencial) que puedan acumularse en el sector bancario en su conjunto, así como la amplificación procíclica de dichos riesgos a lo largo del tiempo.

Si bien, el negocio bancario por definición es riesgoso, al ser los depósitos bancarios de los ahorradores la principal fuente de capitalización de los bancos era necesario delimitar a nivel internacional parámetros mínimos de exposición al riesgo, sobre todo después de las experiencias negativas que provocaron las crisis bancarias y financieras de las últimas dos décadas.

Por ello, no es casual que después del episodio de crisis financiera y bancaria en Méjico (1994-1995) se hayan enmendado los acuerdos de Basilea I y que, derivado de las crisis similares de Asia (1997), Rusia (1988) y Argentina (2001), se hubieran emitido los acuerdos de Basilea II en 2004; 
lo mismo que los que corresponden a Basilea III en 2012, que precedieron a la gran crisis bancaria y financiera que comenzó en EUA en 2008 y que ha tenido alcance internacional.

A pesar de los principios de Basilea, las crisis bancarias siguen apareciendo y afectando prácticamente a todos los países del orbe. Lo anterior atiende a diversas causas, sin embargo, las más evidentes están vinculadas al grado de adopción y cumplimiento de dichos principios por parte de cada país y de sus bancos (así como la importancia sistémica' de estos) y a la adecuada supervisión por parte de los reguladores y, por supuesto, a las condiciones económicas y financieras propias de cada país o región. Sin embargo, al estar la banca y las economías de los países cada vez más globalizadas, la exposición al riesgo aumenta considerablemente; por lo tanto, los acuerdos de Basilea han evolucionado a la par de la crisis de los sistemas financieros en los últimos treinta años.

\section{B. La crisis financiera mejicana de 1994-1995, la adopción de los acuerdos de Basilea y el inicio del fortalecimiento de la banca en Méjico}

La crisis financiera y bancaria que se suscitó en Méjico en 1994-1995, aceleró la adopción de las reglas de Basilea y su incorporación en la regulación nacional, además de que marcó un hito para una serie de reformas que fortalecerían a la banca a lo largo de los siguientes años.

\section{1) Algunos aspectos sobre la crisis financiera 1994-1995}

Aunque las causas y efectos de esta crisis son diversos, en este artículo nos referiremos de manera resumida a los más importantes.

El año 1994 fue particularmente complejo para Méjico desde el punto de vista social y político, comenzando porque había elecciones federales. En enero surgió una rebelión armada al sur del país (Chiapas), comandada por el Ejercito Zapatista de Liberación Nacional (EZLN), misma que se enfrentó con el Ejército Mejicano. En marzo fue asesinado el candidato presidencial del partido oficial Luis Donaldo Colosio. En septiembre fue acribillado en la capital del país el secretario general del partido oficial (PRI), José Francisco Ruíz Massieu, y meses más tarde su hermano Mario renunció a su reciente nombramiento como fiscal encargado de investigar el asesinato de José Francisco, debido a los obstáculos que habría enfrentado. Más tarde, el secretario de Gobernación, Jorge Carpizo, renunció a su cargo (aunque después se retractó) y fue secuestrado Alfredo Harpa, uno de los principales empresarios del país y presidente de uno de los bancos más grandes: Banamex.

Las divisas salían del país presionando al tipo de cambio y disminuyendo las reservas internacionales; había déficit en la cuenta corriente y 
compromisos de pago de deuda externa que comprometían las finanzas públicas. La administración presidencial cambió el $1^{\circ}$ de diciembre y el recién nombrado secretario de Hacienda y Crédito Público, Jaime Serra, reúne a un grupo de empresarios, dueños de bancos y casas de bolsa y anuncia la inminente devaluación de la moneda, dándoles oportunidad de que salieran al mercado cambiario a acabar con los últimos dólares que quedaban en dos días distintos (traicionando el pacto que habrían hecho de no comprar todas las divisas), constituyéndose lo que se denominó el "error de diciembre".

Respecto de esta crisis, Jacobs y Rodríguez-Arana (2003) señalan que en diciembre de 1994 el mercado cambiario en Méjico sufrió un ataque especulativo y, por tanto, una devaluación que, sumado a los pagos sobre la deuda pública que debían hacerse, llevaron al Gobierno Mejicano prácticamente a la insolvencia.

Girón y Levy (2005) apuntan que posterior a ello la estrategia de deuda interna por la vía de la política monetaria, que se impulsó para retener la salida de divisas y contener las presiones sobre el mercado cambiario y el déficit en la cuenta corriente, significó el incremento en las tasas de interés en las emisiones primarias de los títulos de deuda (Cetes, Bondes y Ajustabonos), generando el aumento en las tasas de interés establecida por el Banco de México, lo que, a su vez, incrementó significativamente las tasas de interés que cobran las instituciones de crédito, y como resultado de ello el sistema bancario se debilitó por el súbito aumento en la tasa de morosidad, que culminó con la descapitalización de los propios bancos.

De acuerdo con Banxico (1995), a finales de 1994 el índice de capitalización de la banca alcanzó $9.3 \%$, mientras que para finales de febrero de 1995 había disminuido ya a menos del $8 \%$, inclusive la mitad de los bancos comerciales privatizados presentaban un capital inferior al mínimo requerido.

Los treinta y cinco bancos que operaban en el sistema sufrieron una severa descapitalización para 1995 y tuvieron que ser rescatados por el Gobierno a través del Fobaproa; aunque, de acuerdo con Garrido (2000), hubo discrecionalidad en los criterios con que los créditos fueron adquiridos por este fideicomiso, ya que en promedio esto fue al $70 \%$ de su valor nominal y en montos que duplicaban el capital fresco aportado por los

1 El riesgo sistémico es aquél que se produce al existir temor por la descapitalización de un banco que contagia a los clientes de los demás bancos, quienes, a su vez, retiran masivamente sus depósitos, generando pérdidas de capital que provoca la quiebra del banco que no necesariamente tenía problemas de capitalización en un inicio. 
inversionistas de los bancos, además de que solo fueron intervenidos 11 bancos y los otros 24 siguieron operando con los mismos banqueros que habían generado el problema.

De acuerdo con Guillén (2010), el costo fiscal del programa de salvamento financiero ascendía en marzo de 1999 a más de 750.000 mil millones de pesos (alrededor de 70000 millones de dólares), equivalente al 19\% del PIB (1988) y seis veces el valor de lo que lo bancos pagaron por la reprivatización. Conforme a las estimaciones de Banxico (1995), este monto tardaría treinta años en amortizarse (hasta 2025).

Cárdenas (2010) sostiene que, como consecuencia de lo anterior, el Gobierno creó el Programa de Capitalización Temporal (Procapte), a través del cual se buscaba que los bancos contaran con la capitalización necesaria para hacer frente a sus obligaciones mediante la adquisición de deuda por parte del Fondo Bancario para la Protección del Ahorro (Fobaproa), así como el Programa de Capitalización y Compra de Cartera y otras operaciones de saneamiento de las carteras de los bancos.

Para aliviar los efectos de la crisis financiera (monetaria y bancaria) se recurrió a la asistencia financiera internacional, dando lugar al mayor rescate en la historia del Sistema Financiero Internacional (nacido en Bretton Woods, a mediados de los años cuarenta), pues se facilitaron alrededor de 52.000 millones de dólares en un paquete en el que participaron el Gobierno de EUA, el FMI, el Banco Mundial (BIRF), el Banco Interamericano de Desarrollo (BID), el BIP y el Banco de Canadá.

Específicamente, el BIRF y el BID realizaron en 1995 un préstamo a Méjico por 2,250 millones de dólares para fortalecer el sistema bancario mejicano (ya quebrado para ese entonces), con la condición de que el país realizara una profunda reforma al sistema financiero con énfasis en el mejoramiento de la supervisión bancaria, la regulación prudencial y evitar el riesgo sistémico.

Avendaño (2010 p.225) señala que en los contratos en los que se pactó el citado préstamo, se acordó la obligación del Gobierno Mejicano de realizar una serie de reformas en el Sistema Financiero (condicionalidad), con el propósito de hacerlo más sólido y confiable después de la crisis bancaria.

En el anexo I de los contratos de Préstamo y Garantía del Programa de Reestructuración del Sector Financiero № 3911 ME (SHCP: 2006) se definió una matriz de acciones para modificar políticas públicas, en donde, entre otros compromisos, se pactó requerir capital adicional a aquellos bancos cuyo índice de capitalización fuera menor al 8\%, o bien, que entraran al Procapte (apartado IX.-Reforma a la regulación prudencial 
y el fortalecimiento a la supervisión). Asimismo, se estableció que la CNBV trabajaría en la adecuación y recomposición del capital (Tier 1) para la banca y préstamos con partes relacionadas (apartado II. Acciones para limitar las pérdidas financieras). Otro aspecto que quedó consignado entre las condiciones del préstamo fue el fortalecimiento de las acciones de supervisión por parte de la CNBV.

Al mantener entre sí una estrecha relación los entes financieros internacionales (FMI, BIRF, BID y BPI), las recomendaciones de Basilea fueron rápidamente impulsadas por el BIRF, que en ese entonces estaba facilitando recursos para aliviar la crisis bancaria; por lo que el Gobierno Mejicano tuvo que incorporarlas de manera inmediata.

\section{2) El Fortalecimiento de la banca después de la crisis}

Posterior a la crisis se realizaron una serie de reformas para fortalecer a la banca en Méjico y evitar un episodio similar. Una de las primeras acciones tuvo que ver con incrementar la participación de la inversión extranjera en el sector bancario, que, si bien era inminente debido a la firma del Tratado de Libre Comercio de América del Norte (TLCAN), tuvo que acelerarse y además trajo como consecuencia la reducción del número de bancos por fusiones y adquisiciones.

Girón y Levy (2005) advierten que en febrero de 1995 se permitió el acceso de inversionistas institucionales extranjeros para fortalecer el capital social de los bancos, aunque eso generó competencia desleal para la banca nacional. Sostienen que entre 1989 y 1999 la Ley de Instituciones de Crédito (LIC) se adecuó al proceso económico mediante diferentes modificaciones, para dar congruencia a la desregulación operativa del sistema bancario y cuidar su sano y equilibrado desarrollo y proteger los intereses del público. Para el año 2000 se abre la banca $100 \%$ a la inversión extranjera.

En 1999 se sustituye el Fobaproa por el Instituto de Protección al Ahorro Bancario (IPAB), con lo cual los apoyos financieros en caso de descapitalización y quiebra de la banca dejan de dirigirse a las instituciones de crédito, para beneficiar directamente a los ahorradores a través del seguro de depósito que cubre cada cuenta en los bancos hasta por 400 mil UDI's. $^{2}$

Más recientemente, en 2006, se creó en la LIC el Comité de Estabilidad Bancaria, con el propósito de analizar y, en su caso, determinar asistencia financiera a algún banco que tuviera problemas de capitalización y que por su importancia sistémica debía ser apoyado a fin de salvaguardar los intereses del propio sistema y de los ahorradores. 


\section{3) La Incorporación de los acuerdos de Basilea II y continuación del fortalecimiento de la banca}

El marco de supervisión de la CNBV también se fortaleció a mediados de la década de los años 2000. Por una parte, se expidió un nuevo Reglamento de supervisión de la CNBV y por otra, se realizó un esfuerzo de depuración y mejora regulatoria que dio lugar a la expedición de las Circulares Únicas por parte de dicho órgano, a fin de normar adecuadamente al sector, a través de la Circular Única de Bancos (CUB).

Amunátegui (2006) señala que el acuerdo de Basilea II considera la existencia de un mapa de riesgo en el sector bancario, compuesto básicamente por tres riesgos: a) el riesgo de mercado, asociado a fluctuaciones en el precio de los activos; b) el riesgo de crédito, vinculado a la incertidumbre en el pago de las obligaciones de los deudores; $y$ c) el riesgo de operación que constituye una novedad (pues nace precisamente de este acuerdo) y consiste en la probabilidad de ocurrencia de pérdidas producidas por errores humanos, fallas tecnológicas, fraudes, desastres naturales, deficiencias en los procesos internos, personal y sistemas.

Las recomendaciones de Basiela II se incorporaron en la normativa mejicana precisamente en la CUB.

A través de diversas dispersiones de dicha circular quedó regulada la identificación, administración, registro y cuantificación del riesgo operacional y sus tres componentes (humano, tecnologías de la información y legal).

Otro de los aspectos de Basilea II que quedó reflejado con suficiente detalle en la CUB fue el relativo al índice de capitalización (ICAP), mismo que se utiliza para medir la capacidad de un banco para hacer frente a una demanda de retiro de ahorros por parte de los usuarios; además de que a partir de su medición las autoridades financieras toman decisiones para requerir a los bancos inyección de capital, intervenir en ellos o declarar su quiebra. El ICAP representa la fortaleza financiera de una institución de crédito para soportar pérdidas no esperadas en función de su perfil de riesgo (Expansión 2013:2).

La CUB (CNBV 2016: artículo 220) clasifica a las instituciones de banca múltiple en cuatro categorías en función de su ICAP: categoría I, ICAP = ó + a $10 \%$; categoría II, ICAP = ó + $8 \%$ y - $10 \%$; categoría III, ICAP = ó + $7 \%$ y -8 \%; categoría IV, ICAP = ó + $4 \%$ y - $7 \%$.

2 La Unidad de Inversión (UDI), tiene una equivalencia prácticamente de 6 pesos. Por tanto, el monto del seguro de depósito de cada cuenta bancaria protegida es de 2'400,000.00 al 20 de enero de 2018. 
Un reflejo más de los acuerdos de Basilea II en la CUB se encuentra en la clasificación de los diversos tipos de riesgos, dividiéndolos en cuantificables y no cuantificables. Los cuantificables se dividen, a su vez, en discrecionales como: a) riesgo de crédito; b) riesgo de liquidez y c) riesgo de mercado, y no discrecionales como: a) riesgo tecnológico y b) riesgo legal.

\section{4) La Crisis financiera originada en EUA 2007-2008, la resiliencia de los bancos mejicanos y la adopción de los acuerdos de Basilea III}

\section{a) La crisis financiera 2007-2008 EUA y Basilea III}

La adopción de los acuerdos de Basilea III se manifiesta claramente en el artículo 2 Bis 5 de la CUB (CNBV 2016), en donde se determinó que los bancos deben mantener un capital neto en relación con los riesgos de crédito, de mercado y operacional en que incurran en su operación, que no podrá ser inferior a la cantidad que resulte de sumar los requerimientos de capital por cada uno de dichos tipos de riesgo. Asimismo, establece que el capital neto estará compuesto por una parte básica y otra complementaria. El ICAP mínimo requerido que las Instituciones deben mantener será igual a 8 por ciento. A su vez, tratándose de la parte básica del capital neto, las instituciones deberán mantener: I) un coeficiente de capital básico por lo menos del $6 \%$ y II) un coeficiente de capital fundamental por lo menos de $4.5 \%$. Adicionalmente, las Instituciones deberán mantener un suplemento de capital equivalente al $2.5 \%$ de los activos ponderados sujetos a riesgos totales.

Al igual que en el caso de la crisis financiera de Méjico 1994-1995, no pretendemos hacer un análisis detallado de las causas y consecuencias de la crisis hipotecaria y financiera de EUA de 2008, sin embargo, señalaremos algunos de sus aspectos más relevantes.

Guzmán (2009) sostiene que entre 2004 y 2006 inicia la burbuja inmobiliaria debido al aumento continuo de los precios de las viviendas y se concedió un número importante de créditos para viviendas a personas con escasos recursos (créditos subprime), los cuales estaban garantizados por las hipotecas; sin embargo, funcionaba bajo el esquema de intereses bajos y aumento en el precio de las viviendas. Para 2006 el $46 \%$ de los créditos hipotecarios otorgados fueron de riesgo alto y medio (21\% subprime y $25 \%$ medio). Mientras que las hipotecas prime representaron $36 \%$ y las más seguras solo el $15 \%$.

De acuerdo con el propio Guzmán, otro factor que agravó la crisis fue que para marzo de 2007 el número de créditos morosos afectaba a 6 millones de familias (600.000 millones de dólares). Algunos bancos europeos, como Mitteslstandsbank, IKB, West LB en Alemania y Paribás en 
Francia, entraron en crisis por estar expuestas sus carteras a los créditos subprime. Los bancos centrales de diversos países como EUA, Europa y Asia inyectaron grandes cantidades de recursos para proveer liquidez a los mercados. Los tres bancos más grandes de EUA (Citibank, Bank of America y JP Morgan) fueron rescatados por el gobierno de EUA.

Para 2008 se comenzó a nacionalizar bancos en Inglaterra (Northern Rock) Francia, Bélgica (Dexia) e Islandia y otros cerraron como el alemán WeserBank. Las hipotecarias Freddie Mac y Fannie Mae, se colocaron bajo la tutela del Departamento del Tesoro de EUA. Continuaron quebrando instituciones financieras en EUA, entre ellas Lehman Brothers, lo cual aumentó la espiral negativa y agravó la crisis. La aseguradora AIG también fue rescatada por el Gobierno. Un análisis sobre los alcances de estas quiebras ha sido claramente descrito por Verón (2010).

Comenzó entonces la asistencia financiera de organismos internacionales como el FMI a Islandia, Hungría y Ucrania. Los bancos centrales de EUA, diversas economías de Europa y Japón comenzaron a bajar sus tasas de interés y anunciaron que entrarían en recesión.

En el caso de EUA, de acuerdo con la Federal Deposit Insurance Corporation (2018), quebraron 510 bancos entre 2007 y 2014, como se muestra a continuación.

Cuadro 4. Número de bancos quebrados por año en EUA (2007-2014)

\begin{tabular}{|c|c|c|c|c|c|c|c|}
\hline 2007 & 2008 & 2009 & 2010 & 2011 & 2012 & 2013 & 2014 \\
\hline 3 & 25 & 140 & 157 & 92 & 51 & 24 & 18 \\
\hline
\end{tabular}

Fuente: Federal Deposit Insurance Corporation. Bank Failures in Brief, Washington, 2018. https://www.fdic.gov/bank/historical/bank/2014/index.html

Claramente se ven los efectos más grandes de la crisis entre 2008 y 2012, cuando 464 bancos quebraron.

De acuerdo con la evaluación del Comité de Basilea sobre la consistencia regulatoria de Basilea III en EUA (2014), el enfoque estandarizado para el riesgo de mercado generó una desviación que impactóficientes de capital no incluyeronn EUAe.cado cambiario a acabar con los rios, dueños de bancos y casas de bolsa y anuncia la in negativamente en el capital de algunos bancos, debido entre otras razones al enfoque basado en calificaciones internas respecto del riesgo de crédito; lo que no era con los principios de Basilea. En el reporte se identificaron desviaciones importantes en varios de los principales bancos de EUA, debido a que los coeficientes de capital no incluyeron un cargo de capital separado por riesgo operativo y ajuste de valor de crédito. 
Las agencias del Gobierno de EUA no estuvieron de acuerdo con las conclusiones del reporte bajo el argumento de que el enfoque de supervisión simplificada de EUA difiere de los principios de Basilea. Tampoco coincidieron con los hallazgos del análisis respecto al riesgo de mercado en ese país, pues sostienen que no pueden aplicarse los principios de ese organismo internacional de la misma manera en todos los países miembros de Basilea.

\section{b) Las consecuencias de la crisis financiera de 2007-2008 en Méjico y la resiliencia de la banca mejicana}

Del análisis que se ha hecho sobre fortalecimiento del sistema bancario a partir 1995, se advierte que la banca mejicana era menos vulnerable ante la inminente crisis, debido a que el Gobierno había promovido modificaciones normativas, la adopción de los principios de Basilea y mejorado la supervisión.

Warman (2013) sostiene que si bien la crisis financiera (2007-2008) no afectó a la banca en países de América Latina, el fortalecimiento del capital regulatorio ayudaría al sistema bancario de cualquier país en un escenario de dificultades de los bancos. En su estudio, Warman hace un análisis comparativo sobre el índice de adecuación de capital (capital regulatorio/activos ponderados sujetos a riesgo), de acuerdo con BASILEA III, arrojando lo siguientes resultados:

Cuadro 5. Índice de capitalización de la banca en América Latina (2013)

\begin{tabular}{|l|c|c|}
\hline \multicolumn{1}{|c|}{ País } & $\begin{array}{c}\text { Observado en diversas } \\
\text { fechas }\end{array}$ & Basilea III sin transitoriedad \\
\hline Méjico & 16.3 & 14.1 \\
Brasil & 15.4 & 10.3 \\
Argentina & 14.5 & 13.8 \\
Chile & 13.3 & 10.3 \\
Uruguay & 12.5 & 11.2 \\
Colombia & 15.3 & 14.6 \\
Guatemala & 14.5 & 13.7 \\
Honduras & 14.7 & 13.0 \\
Paraguay & 16.3 & 13.4 \\
Venezuela & 13.8 & n.d. \\
\hline
\end{tabular}

Fuente: WARMAN, Fanny. Integración del capital regulatorio en países latinoamericanos y efectos de Basilea III. Boletín del CEMLA, Méjico, julio-septiembre, 2013, p. 170 http://www.cemla.org/PDF/investigacion/inv-2013-12-14.pdf 
Puede advertirse que Méjico, prácticamente, es el país con la mejor posición respecto del cumplimiento de Basilea III, en las principales economías de América Latina.

La solidez del sistema bancario mejicano, debido a la evolución y fortalecimiento prudencial, regulatorio y de supervisión, ya había sido advertido por Avendaño (2008), al señalar que "se puede concluir también que no solo se ha recobrado la confianza en el Sistema Financiero Mejicano, sino que se encuentra lo suficientemente regulado y supervisado para evitar colapsarse en caso de una crisis financiera como la ocurrida en 1994".

A pesar de la crisis financiera de 2007-2008 y de la quiebra de diversos bancos en EUA y Europa, la banca mejicana se mantuvo bien capitalizada antes y después de la crisis, lo cual puede advertirse al revisar la evolución del ICAP a lo largo de los años, en donde se aprecia que en el período 2006-2016 este indicador se mantuvo estable entre el $15 \%$ y el $16 \%$ (por encima del mínimo requerido por BASILEA que es de $8 \%+2.5 \%$ ), como puede apreciarse en siguiente tabla:

Cuadro 6. Evolución del ICAP de la banca múltiple (CNBV 2016), por año:

\begin{tabular}{|c|c|c|c|c|c|c|c|c|c|c|c|}
\hline 은 & ర్రి & 요 & ஜ̊ & 8̊ & 융 & 둥 & $\frac{N}{8}$ & $\frac{m}{\stackrel{ก}{ก}}$ & $\frac{\pi}{8}$ & 뭉 & $\frac{0}{8}$ \\
\hline 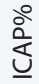 & 16.1 & 15.9 & 15.3 & 16.5 & 16.8 & 15.7 & 16 & 15.5 & 15.8 & 15 & 14.9 \\
\hline \multicolumn{11}{|c|}{ Promedio total } & 15.7 \\
\hline
\end{tabular}

Fuente: Elaboración propia a partir de la información contenida en: Portafolios de información (2016), R1 Índice de Capitalización. Comisión Nacional Bancaria y de Valores http://portafoliodeinformacion.cnbv.gob.mx/bm1/Paginas/alertas.aspx, Méjico

Incluso, si se mide el ICAP de los cinco principales bancos de Méjico en el mismo período, veremos una tendencia prácticamente igual al de toda la banca (15\% de ICAP) en el mismo periodo, como se verá a continuación:

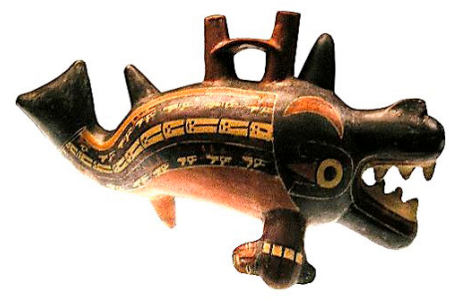


Cuadro 7. Evolución anual del ICAP de los cinco mayores bancos (CNBV 2017).

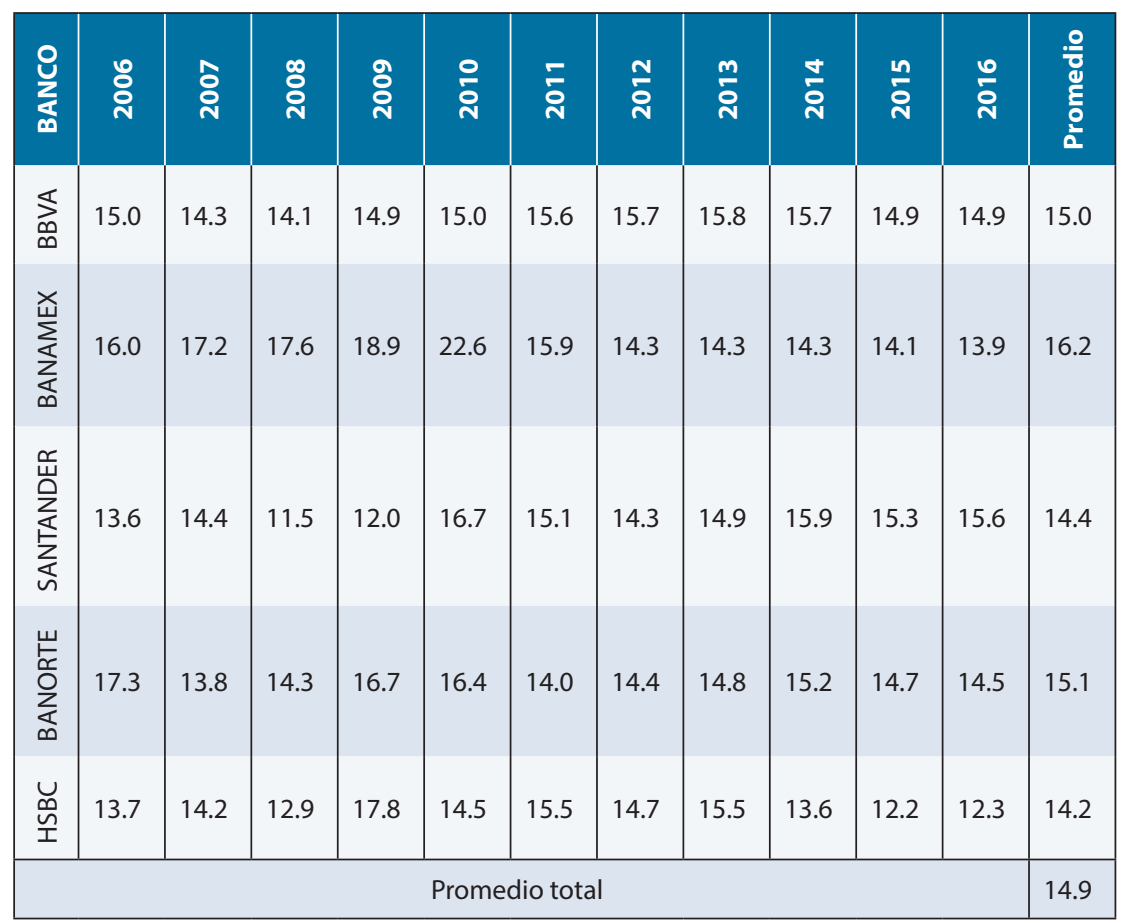

Fuente: Elaboración propia a partir de la información contenida en: Portafolios de información (2018), R1 Índice de Capitalización. Comisión Nacional Bancaria y de Valores http://portafoliodeinformacion.cnbv.gob.mx/bm1/Paginas/alertas.aspx, Méjico

Otro hecho que demostró la solidez de la banca mejicana es que nuestro país fue uno de los primeros en adoptar, a nivel internacional, los acuerdos de Basilea III (Expansión CNN, 2013).

Asimismo, la Organización para la Cooperación y el Desarrollo Económicos (OCDE:2017), al referirse al entorno económico de Méjico, sostiene que los riesgos para la estabilidad financiera están bien controlados, debido a las estrategias de cobertura, las reformas regulatorias para acatar los acuerdos de Basilea III y la supervisión, que han ayudado a proteger al sector bancario.

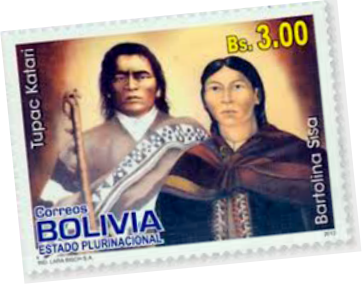




\section{c) La adopción del gobierno corporativo en los Bancos también fortaleció a la banca en Méjico.}

\section{Los principios en materia de gobierno corporativo de la OCDE y el G-20 y su adopción en Basilea y en la banca mejicana}

Los principios en materia de gobierno corporativo (GC) fueron emitidos por la OCDE en 1999 y su última revisión se hizo en 2015. De acuerdo con este organismo, el objetivo del gobierno corporativo es

"facilitar la creación de un ambiente de confianza, transparencia y rendición de cuentas necesario para favorecer las inversiones a largo plazo, la estabilidad financiera y la integridad de los negocios (...) e implica el establecimiento de un conjunto de relaciones entre la dirección de la empresa, su consejo de administración, sus accionistas yotros actores interesados", además de que ayudan a los legisladores a evaluar y mejorar el marco legislativo, reglamentario e institucional del gobierno corporativo, con el objeto de favorecer la eficiencia económica, la estabilidad financiera y el crecimiento económico sostenible" (OCDE, 2015: 3-7).

Basilea adoptó dichos principios para la banca y emitió el documento denominado "Mejoras del gobierno corporativo en organizaciones bancarias" (Basilea, 2006:3), en donde señaló que

"Unas prácticas eficaces de gobierno corporativo resultan esenciales para conseguir y mantener la confianza del público en el sistema bancario, algo esencial para el adecuado funcionamiento del sector bancario y de la economía en su conjunto. Las insuficiencias en el gobierno corporativo pueden acabar en quiebra bancaria, que a su vez puede acarrear costes y efectos significativos de dimensiones públicas por su impacto potencial en los esquemas de seguro de depósito aplicables y por sus posibles implicaciones macroeconómicas, como el riesgo de contagio o el impacto en los sistemas de pago".

A partir del documento antes citado, Basilea emitió ocho principios para un buen GC en los bancos, dirigidos principalmente al Consejo de Administración, relativos a: comprender claramente sus funciones en el GC (P1); aprobar y vigilar los objetivos estratégicos (P2); establecer líneas claras de responsabilidad (P3); adecuado seguimiento de las políticas (P4); apoyarse en las funciones de auditoría y control interno (P5); políticas retributivas congruentes (P6); fomentar la transparencia y eliminar obstáculos a la misma; (P7 y 8) 


\section{La adopción de los principios de gobierno corporativo en las instituciones de crédito mejicanas}

En nuestro país la legislación bancaria fue la primera en adoptar reglas en materia de gobierno corporativo desde 1991, al establecer la composición e independencia del consejo de administración (25\% al menos). De igual manera, desde 2008 dicho consejo debe contar con un comité de auditoría que lo apoye en sus funciones.

La LIC ha incorporado diversas disposiciones en materia de gobierno corporativo para fortalecer la banca, como por ejemplo: contar con un comité de auditoría, (art. 21), abstenerse los consejeros de votar en casos de conflicto de interés (art. 22 Bis y 23), establecer un comité de remuneraciones (art. 24 Bis2), autorización previa para realizar operaciones con personas relacionadas (art. 73 Bis), transparentar información corporativa, financiera, administrativa, operacional, económica y jurídica y honorabilidad de los auditores externos (art. 101 Bis).

Por otra parte, en la CUB (arts., 140-144, 154, 159, 164, 166 y 168 Bis ) se plasmaron diversas disposiciones para fortalecer el gobierno corporativo en las IBM, particularmente para mantener un sólido sistema de control interno y remuneraciones a través de diversas atribuciones para el Consejo.

\section{Conclusiones}

Los acuerdos de Basilea han evolucionado; conforme las crisis financieras de los últimos treinta años han aparecido en diversos países y regiones del mundo, y aun cuando su aplicación ha sido distinta en cada uno de ellos, Méjico ha optado por incorporarlos de manera permanente en su regulación, fortaleciendo con ello el marco prudencial de la banca.

Derivado de la asistencia financiera recibida en Méjico con motivo de la crisis financiera y bancaria que sufrió el país en 1994-1995, y por virtud de las condiciones que impusieron algunos organismos financieros internacionales como el BIRF, Méjico comenzó una serie de reformas para mejorar la supervisión y mitigar los riesgos en los bancos, cuya evolución a lo largo de diez años (1995-2005) le permitió alejarse significativamente de los riesgos por contagio de crisis iniciadas en otros países como la surgida en EUA en 2007-2008.

La adecuación y emisión de leyes y disposiciones administrativas como las emitidas por la CNBV en materia de banca, la creación de mecanismos de protección al ahorrador, así como el diseño y fortalecimiento institucional de los supervisores de la banca, promovidos por los propios organismos financieros internacionales a partir de la crisis financiera mejicana de 
1994-1995, también han contribuido a la estabilidad del sistema bancario mejicano de los últimos quince años.

El cumplimiento en Méjico de los acuerdos de Basilea y de las reglas de gobierno corporativo (OCDE-G20), favoreció que Méjico haya conservado un buen nivel de capitalización de los bancos, incluyendo los más grandes, durante la crisis de los sistemas bancarios de EUA y de algunos países de Europa, durante 2007-2009, inclusive por encima de los países menos afectados como los de América Latina.

\section{Referencias Bibliográficas}

1. AmUNATEGUI, Andrés. (2006). Aspectos Jurídicos de Basilea II. Mercado Bancario y Asegurador. En: Revista Chilena de Derecho Privado, № 6. Santiago de Chile: Fundación Fueyo-Universidad Diego Portales.

2. AVENDAÑO, Octavio (2008). La creación de normas jurídicas en el marco de la nueva arquitectura financiera internacional. [Tesis doctoral]. UNAM, Ciudad de Méjico.

3. AVENDAÑO, Octavio. (2010). El Sistema Financiero Internacional. Instituciones y Crisis Financieras. Ciudad de Méjico: Porrúa.

4. BANCO DE PAGOS INTERNACIONALES. (2009). La mejora del gobierno corporativo en organizaciones bancarias. Comité de Supervisión Bancaria de Basilea-BCBS. Basilea, Suiza.

5. BANCO DE MÉXICO. (2015). Informe Anual 1995 Méjico. Disponible en Internet: http://www.banxico.org.mx. Consultado el 15.01.2018

6. CÁRDENAS, Enrique. (2010). La reestructuración económica de 1982 a 1994. (pp.182-240). En: Servín, Elisa (Coordinadora), Del nacionalismo al neoliberalismo, 1940-1994. Méjico: Fondo de Cultura Económica.

7. COMITÉ DE SUPERVISIÓN BANCARIA DE BASILEA. (2013). Carta Estatutaria, Basilea. Disponible en Internet: https://www.bis.org/bcbs/charter_es.pdf. Consultado el 22.12.2016

8. COMITÉ DE SUPERVISIÓN BANCARIA DE BASILEA (2006). Principios básicos para una supervisión bancaria eficaz. Disponible en Internet: http://www.bis.org/ publ/bcbs129esp.pdf. Consultado el 22.12.2016

9. COMITÉ DE SUPERVISIÓN BANCARIA DE BASILEA. (2004). Aplicación de Basilea II: aspectos prácticos. Disponible en Internet: http://www.bis.org/publ/bcbs109esp. pdf. Consultado el 22.12.2016

10. COMITÉ DE SUPERVISIÓN BANCARIA DE BASILEA (2014). Evaluación sobre la consistencia regulatoria de BASILEA III en EUA. Disponible en Internet: https:// www.bis.org/bcbs/publ/d301.pdf. Consultado el 10.01.2018 
11. EXPANSIÓN. (2013). Bancos, fuertes en índices de capital. Disponible en Internet: http://expansion.mx/economia/2013/09/17/bancos-en-mexico-fuertes-antemorosos. Méjico. Consultado el 25.11.2016

12. EXPANSIÓN. (2013), Méjico inaugura normas de Basilea III. Disponible en Internet: http://expansion.mx/economia/2013/01/01/mexico-inaugura-basilea-iii. Méjico. Consultado el 25.11.2016

13. EXPANSIÓN. (2013) Bancos, fuertes en índices de capital. Disponible en Internet: http://expansion.mx/economia/2013/09/17/bancos-en-mexico-fuertes-antemorosos Méjico. Consultado el 25.11.2016

14. FEDERAL DEPOSIT INSURANCE CORPORATION. Bank failures in brief. (2018). Disponible en Internet: https://www.fdic.gov/bank/historical/bank/2014/index. html. Consultado el 10.01.2018

15. GARRIDO, Celso. (2000). Crisis financiera y desarrollo económico en Méjico. Factores estructurales y desafíos para el futuro, Méjico. En: El Cotidiano, Vol. 16, № 102, julio-agosto. Méjico: Universidad Autónoma Metropolitana, Unidad Azcapotzalco.

16. GIRÓN, Alicia y LEVY, Noemí. (2005). Méjico: los bancos que perdimos. De la desregulación a la extranjerización del sistema financiero. Méjico D.F.: Instituto de Investigaciones Económicas y Facultad de Economía, UNAM.

17. GUILLÉN, Arturo. (2000). Méjico hacia el siglo XXI. Crisis y modelo económico alternativo, $2^{\text {a }}$ ed., Méjico: UAM-Plaza Valdés.

18. GUZMÁN, Manuel. (2009). Méjico Frente a la Crisis. Méjico D.F.: LID Editorial Mexicana.

19. IFAl. SHCP. (2006). Contratos de Préstamo y Garantía del Programa de Reestructuración del Sector Financiero y documentos relacionados, № $3911 \mathrm{ME}$, 1995, solicitud de información. Méjico DF, Méjico.

20. JACOBS, Gerardo y RODRíGUEZ-ARANA, Alejandro. (2003). La crisis de 19941995 en Méjico: causas, desarrollo y solución. En: Varela, Félix y Jacobs, Gerardo, Crisis Cambiarias y financieras, una comparación de dos crisis (75-135). Madrid: Ediciones Pirámide.

21. LIZARZABURU, Edmundo R.; BERGGRUN, Luis y QUISPE, Julio. (2012). Gestión de riesgos financieros. Experiencia en un banco latinoamericano. En: Revista Estudios Gerenciales, Vol. 28, № 125 Santiago de Cali: ICESI.

22. MARTínEZ, Carlos (2007). Basilea II, retos y oportunidades hacia una mayor armonización de la regulación y supervisión financiera en el siglo XXI. En: Revista Gestión y Política Pública, Vol.XVI No2. Méjico: CIDE.

23. MÉJICO. Comisión Federal de Competencia Económica. (2014). Trabajo de investigación y recomendaciones sobre las condiciones de competencia en el sector financiero y sus mercados. Resumen ejecutivo. Disponible en Internet: 
https://www.cofece.mx/cofece/images/Estudios/ResumenEjecutivo26-09-14. pdf. Consultado el 28.11.2016

24. MÉJICO. Comisión Nacional Bancaria y de Valores. (2016). Disposiciones de carácter general aplicables a las instituciones de crédito. Circular Única de Bancos. Secretaría de Hacienda y Crédito Público. Méjico D.F.: Méjico.

25. MÉJICO. Comisión Nacional Bancaria y de Valores. (2015). Nota Técnica: Basilea III en Méjico. Disponible en Internet: http://www.cnbv.gob.mx/Documents/ Basilea\%203\%20en\%20M\%C3\%A9xico\%20 (v16). PDF. Consultado el 18.12.2016

26. MÉJICO. Comisión Nacional Bancaria y de Valores. (2017). Portafolios de información. Disponible en Internet: http://portafoliodeinformacion.cnbv.gob. mx/bm1/Paginas/alertas.aspx. Consultado el 02.01.2017. MÉJICO. Congreso de los Estados Unidos Mexicanos. (2014). Ley de Instituciones de Crédito. Diario Oficial de la Federación: 18 de julio de 1990. Méjico D.F., Méjico.

27. ORGANIZACIÓN PARA LA COPERACIÓN Y DESARROLLO ECONÓMICO. (2015). Principios de gobierno corporativo de la OCDE y del G-20. París. Disponible en Internet: http://www.oecd.org/publications/g20-ocde-principios-de-gobiernocorporativo-9789264259171-es.htm. Consultado el 18.10.2016

28. ORGANIZACIÓN PARA LA COPERACIÓN Y DESARROLLO ECONÓMICOS. (2017). Estudios Económicos de la OCDE Méjico 2017. París. Disponible en Internet: https://www.oecd.org/eco/surveys/mexico-2017-OECD-Estudios-economicosde-la-ocde-vision-general.pdf. p.15. Consultado el 23.01.2018

29. TELLO, Carlos. (2006). La nacionalización de la banca en Méjico, 6a Ed. Méjico: Siglo XXI Editores.

30. VERON, Nicolás. (2013). La crisis bancaria en Europa, Anuario Internacional CIDOB. Disponible en Internet: http://www.raco.cat/index.php/AnuarioCIDOB/ article/viewFile/199768/267177. Consultado el 3.10.2016

31. WARMAN, Fanny. Integración del capital regulatorio en países latinoamericanos y efectos de Basilea III. Boletín del CEMLA, Méjico, Julio-septiembre, 2013, Pp.151. Disponible en Internet: http://www.cemla.org/PDF/investigacion/inv-2013-1214.pdf. Consultado el 27.01.2018

Para citar este artículo:
Avendaño, Octavio. (2018). Fortalecimiento de la banca en Méjico después de la crisis 1994-1995, y sus efectos. Teuken Bidikay Vol. 09 №13. Medellín: Politécnico Colombiano. Pp. 81-101 
Lugar sagrado para los habitantes de la capital más alta del mundo, símbolo y guardián de La Paz, la hermosa Illimani es la segunda montaña de la Cordillera Real y de sus entrañas brota la vida en forma de agua. Esta majestuosa montaña de roca y nieve, debe su nombre a la leyenda de Illi y Mana, quienes vivieron una trágica historia de amor, cuyo final recuerda el tiempo en que la psiquis ancestral era una unidad de naturaleza y hombre en equilibrio. Cuenta la leyenda que Illi, hijo de Huiracocha, y Mana, hija de Keshua, se enamoraron y decidieron casarse a pesar de la rivalidad entre las familias y la desventura anunciada por sus padres. Pero la boda no se cumplió. La nieve de su vestido de novia cubrió la roca en que Keshua convirtió a Mana para alejarla de Illi, pero Huiracocha, queriendo aliviar el dolor de su hijo, lo transformó en la brisa que acaricia la montaña. Desde entonces, Illi cuida de su amada y ya no se separarán nunca.

Martha Elena Martínez V.

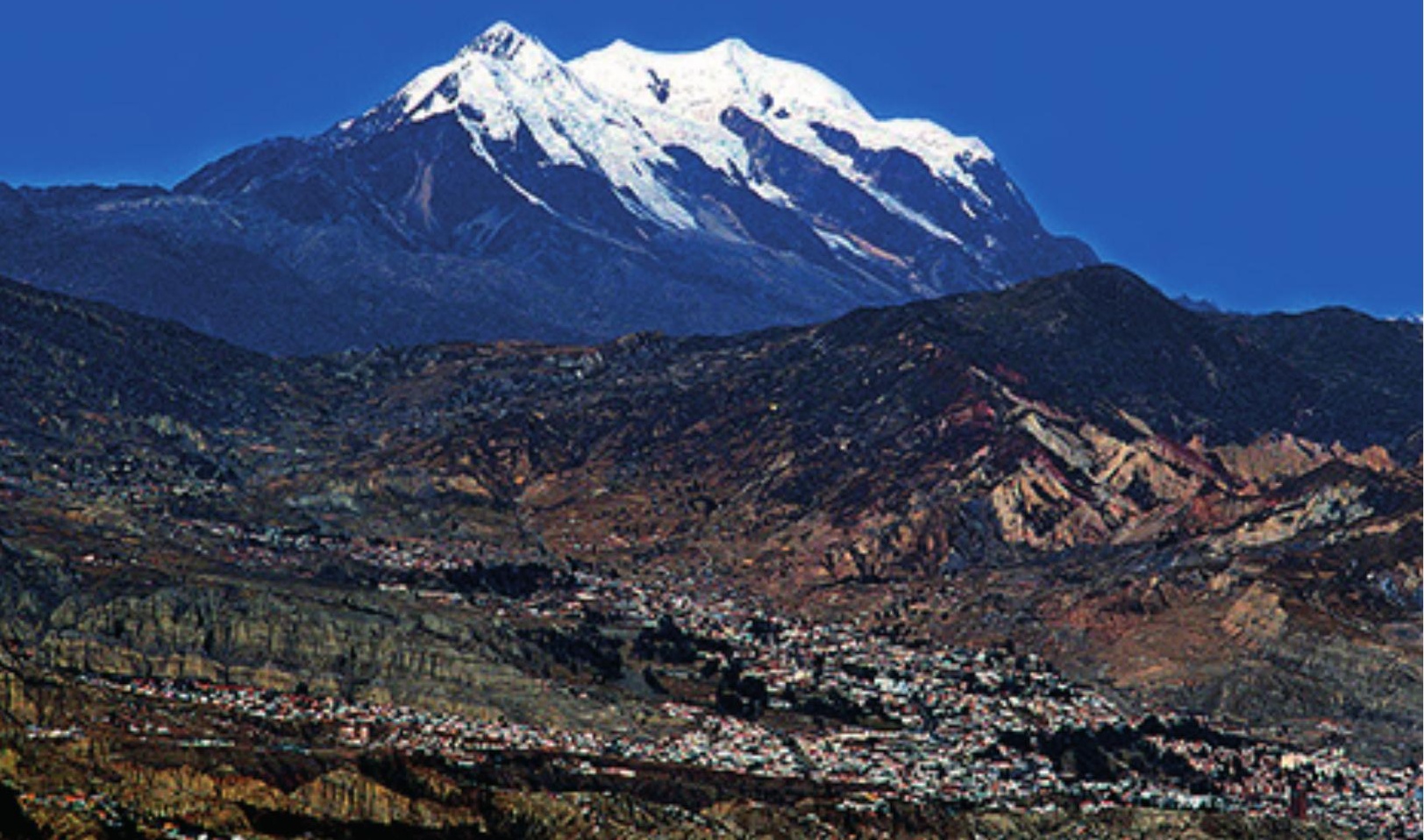

